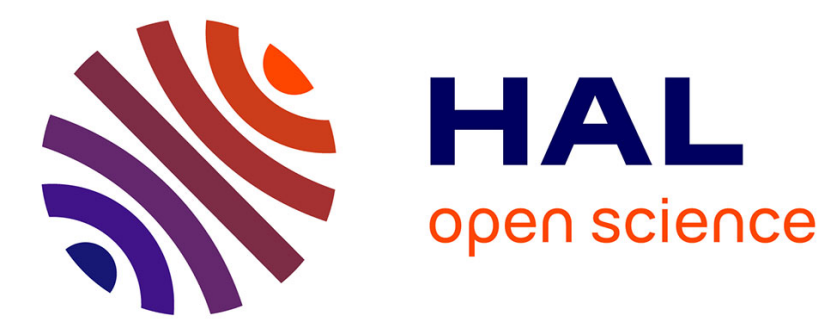

\title{
LITHIUMLIKE-IONS (Al10+ TO TI19+) CALCULATED DATA FOR X-UV LASERS
}

\author{
H. Guennou, A. Klisnick, C. Möller, A. Sureau
}

\section{To cite this version:}

H. Guennou, A. Klisnick, C. Möller, A. Sureau. LITHIUMLIKE-IONS (Al10+ TO TI19+) CALCULATED DATA FOR X-UV LASERS. Journal de Physique Colloques, 1989, 50 (C1), pp.C1-609-C1613. 10.1051/jphyscol:1989167 . jpa-00229367

\section{HAL Id: jpa-00229367 https://hal.science/jpa-00229367}

Submitted on 1 Jan 1989

HAL is a multi-disciplinary open access archive for the deposit and dissemination of scientific research documents, whether they are published or not. The documents may come from teaching and research institutions in France or abroad, or from public or private research centers.
L'archive ouverte pluridisciplinaire HAL, est destinée au dépôt et à la diffusion de documents scientifiques de niveau recherche, publiés ou non, émanant des établissements d'enseignement et de recherche français ou étrangers, des laboratoires publics ou privés. 
JOURNAL DE PHYSIQUE

Colloque C1, supplément au $\mathrm{n}^{\circ} 1$, Tome 50, janvier 1989

LITHIUMLIKE-IONS (A1 $1^{10+}$ TO $\left.\mathrm{T}^{19+}\right)$ CALCULATED DATA FOR X-UV LASERS

H. GUENNOU, A. KLISNICK, C. MÖLLER and A. SUREAU

Laboratoire de Spectroscopie Atomique et Ionique, CNRS UA-775(1), Université Paris-Sud, Bât. 350, F-91405 orsay Cedex, France

\begin{abstract}
Rósume. Dans le cadre des recherches sur les lasers à rayons $X$ utilisant la recombinaison d' ions héliumoïdes en ions lithiumoïdes ( par captures d'électrons libres) au sein d'un plasma chaud qui se détend en se refroidissant, nous présentons un ensemble de données spectroscopiques nécessaires pour mettre en cuvre une modélisation des populations des états excites. Des estimations de gain de rayonnement pour des transitions $3-4,3-5$ et 4-5 d'ions lithiumoïdes, selon les conditions de température et de densité du plasma, sont aussi présentées.
\end{abstract}

Abstract Within the framework of X-ray laser research using the recombination of heliumlike ions with free electrons to produce lithiumlike ions in expending and cooling hot plasmas, we present a set of spectroscopic data required to achieve a modelling of the excited-states populations. Estimates of radiation gain for 3-4, 3-5 and 4-5 transitions of lithiumlike ions, according to the plasma temperature- and density-conditions, are also presented.

\title{
I-INTRODUCTION:
}

During the cooling phase of a laser-produced plasma, the recombination of He-like ions with free electrons producing LI-like ions is mainly achieved by two ways : the radiative recombination to the low-lying levels, essentially those of the $1 s^{2} 2 s$ and $1 s^{2} 2 p$ configurations, and the (three-body) collisional recombination to the highly excited $1 s^{2} n l_{\mathfrak{J}}$ Rydberg levels. At the same time, radiative and collisionally-induced transitions between all the levels occur. In this complex process, transient population inversions appear between $n=3, n=4$, and $n=5$ levels of $L\}$-like lons. Both observed and predicted results have been reported (see for example ref./ $1 /$ and references in it). The wavelengths of the corresponding transitions, such as $3 d-4 f, 3 d-5 f$, or $4 f-5 g$, are situated in the $X-U V$ range for the elements considered in this work.

The story of the population densities of the different tonic levels, in the plasma, can be estimated using a collisional-radiative model $/ 2 /$ coupled with a simulation of the plasma mydrodynamics $/ 3 /$. A lot of atomic dala are required for this : wavelengths, radiative transitions probabilities, collisional rates, fonisation and recombination coefficients.

In this work, we present the most recent results that we have obtained in this way. In addition, we compare the evolution through the isoelectronic series with mydrogenic scaling laws. Actually, apart from the autoionising levels which are not concerned here, the lithiumlike states present some features which correspond to hydrogenic systems but two principal differences occur : the levels of a same configuration are separated not only by the relativistic interactions (mainly spin-orbit) but aiso by the Coulomb interactions between the electrons, and the n principal quantum number sequence

\footnotetext{
(1) Equipe utilisatrice du LULI (Laboratoire pour I'Utilisation des Lasers Intenses, Ecole Polytechnique, F-91128 Palaiseau, France)
} 
begins at $n=2$, the corresponding "ground" level being rendered inaccessible by the presence of the closed $K$ shell

\section{II-ATOMICDATA:}

Energies and wavefunctions of atomic (ionic) states are calculated by a direct SCF method of numerical multiconfigurational Hartree-Fock type including the spin-orbit term of the Pauli approximation, allowing a direct calculation in the intermediate coupling scheme $/ 4 /$. For the ions studied in this work, as it has been shown in ref. $/ 1 /$ for the Cu26+ ion, the electric-dipole transitions are sufficiently dominant above other transition types as long as processes involving $K$ shell yecancies are not considered. So, non electric-dipole transitions between Li-like levels are not considered hereafter.

.The line strength $S_{i j}$ of a transition is given by the square of the reduced matrix- element (iller Ilj) easily obtained from the wavefunctions. The absorption oscillator strength $f_{j i}$ is given by the relation

$$
f_{j i}=(2 / 3) h \psi S_{i j} / g_{j}
$$

where hv and $\mathrm{S}_{\mathrm{ij}}$ are expressed in atomic units; hw is equal to $\mathrm{E}_{\mathrm{i}}-\mathrm{E}_{\mathrm{j}}$, the energy difference between the upper level $i$ and the lower level $j$, and $g_{j}$ is the statistical weight of the level $j$. The probability of spontaneous emission $A_{i j}$ is

$$
A_{i j}=\left(S_{i j} / g_{j}\right) 64 \pi^{4} /\left(3 h \lambda^{3}\right)
$$

$\lambda$ being the wavelength of the transition. If $S_{i j}$ is expressed in atomic unit, $\lambda$ in $\AA$, and $A_{i j}$ in $s^{-1}$, this becomes

$$
A_{i j}=2.026 \times 10^{18} S_{i j} /\left(g_{j} \lambda^{3}\right)
$$

The collisional rates (excitations and de-excitations) are calculated from the $f_{j i}$ 's by the Van Regemorter formula $/ 5 /$. The tonisation and recombination coefficients are given by the formulae of Seston /6/.

Table I shows wavelengths and transition probabilities for radiative spontaneous emission in the $X$-UV range from $n=5$ to $n=3, n=4$ to $n=3$, and $n=5$ to $n=4$ between the $\left.1 s^{2} n\right\}_{j}$ levels of the $\mathrm{Cl}^{14+}, \mathrm{K}^{16+}, \mathrm{Ca}^{17+}$ and $\mathrm{Ti}^{19+}$ ions. Analogous data for $\mathrm{Al}^{10+}$ and $\mathrm{S}^{13+}$ are reported in ref. $/ 2 /$. In Table 1 , the wavelengths are presented in the increasing order for $\mathrm{K}^{16+}$. This introduces a few inversions in the lists of the other ions

In Tables II and III, a limited number of transitions are selected to analyse the dependance of their wayelengths and probabilities with respect to the atomic number $Z$ (i.e. the nuclear charge) and compare it with hydrogenic laws relative to a $(Z-0)$ nuclear charge where 0 is a screening parameter:

$$
\begin{aligned}
\lambda(\text { in } A)= & 911.267\left(1 / n^{2}-1 / n^{2}\right)^{-1}(Z-\sigma)^{-2} \\
& A /(Z-0)^{4}=\text { constant }
\end{aligned}
$$

\section{III-POPULATION DENSITIES IN PLASMAS:}

The population densities of the excited levels of Li-like jons are calculated by the method already used in previous works $/ 1,2 /$. Plasma density and temperature, and ionic fractions, can be taken as parameters or given by a hydrodynamics simulation code. $N_{j}$ being the population density of the level $i$, the reduced population is $\mathrm{N}_{\mathrm{i}} / \mathrm{g}_{\mathrm{j}}$ and the density of inversion between an upper level $u$ and a lower level l is $\Delta n_{u l}=N_{u} / g_{u}-N_{l} / g_{1}$. The values of the inversion densities are provided by the collisional-radiative model. In case of positive inversion density, a gain $6(>0)$ of radiation is obtained at the wavelength of the corresponding transition. Expressing the inversion density $\Delta n$ in $\mathrm{cm}^{-3}$, the product $\mathrm{KT}$ (where $T$ is the temperature) in $\mathrm{eV}$, the line strength $S$ in atomic unit, and the 
Iable 1: Calculated wavelengths $\lambda$ (in $A$ ) and spontaneous emission probabilities $A$ (in (ns) $)^{-1}$ ) for transitions from $1 s^{2} \mathrm{n}^{1} \mathrm{l}_{\mathrm{j}}$ to $1 \mathrm{~s}^{2} \mathrm{nl}_{\mathrm{j}}$ in the $\mathrm{Cl}^{14+}, \mathrm{K}^{16+}, \mathrm{Ca}^{17+}$ and $\mathrm{Ti}^{19+}$ ions. The wavelengths are accurate to within a few per thousand.

\begin{tabular}{|c|c|c|c|c|c|c|c|c|c|}
\hline \multirow[b]{2}{*}{ nl $J$} & \multirow[b]{2}{*}{$n^{\prime} l^{\prime} J '$} & \multicolumn{2}{|c|}{$\mathrm{Cl}^{14+}$} & \multicolumn{2}{|c|}{$K^{16+}$} & \multicolumn{2}{|c|}{$\mathrm{Ca} 17+$} & \multicolumn{2}{|c|}{$\mathrm{Ti}^{19+}$} \\
\hline & & $\lambda$ & $A$ & $\lambda$ & $A$ & $\lambda$ & A & $\lambda$ & A \\
\hline $351 / 2$ & $5 p 3 / 2$ & 54.28 & 78 & 42.48 & 131 & 37.98 & 165 & 30.88 & 252 \\
\hline & $1 / 2$ & 54.32 & 79 & 42.52 & 133 & 38.02 & 168 & 30.92 & 257 \\
\hline $3 p 1 / 2$ & $5 d 3 / 2$ & 56.01 & 145 & 43.65 & 239 & 38.94 & 300 & 31.56 & 458 \\
\hline $3 / 2$ & $5 / 2$ & 56.20 & 174 & 43.83 & 286 & 39.13 & 359 & 31.74 & 547 \\
\hline & $3 / 2$ & 56.21 & 29 & 43.84 & 48 & 39.14 & 60 & 31.75 & 91 \\
\hline $1 / 2$ & $5 s 1 / 2$ & 56.61 & 20 & 44.05 & 31 & 39.29 & 39 & 31.80 & 58 \\
\hline $3 / 2$ & $"$ & 56.81 & 40 & 44.25 & 64 & 39.49 & 80 & 32.00 & 120 \\
\hline $3 \mathrm{~d} 3 / 2$ & $5 f 5 / 2$ & 56.89 & 216 & 44.29 & 356 & 39.50 & 448 & 3199 & 682 \\
\hline $5 / 2$ & $7 / 2$ & 56.94 & 231 & 44.34 & 380 & 39.55 & 477 & 32.04 & 727 \\
\hline & $5 / 2$ & 56.95 & 15 & 44.35 & 25 & 39.56 & 32 & 32.05 & 48 \\
\hline $3 / 2$ & $5 p 3 / 2$ & 57.05 & .9 & 44.39 & 1.4 & 39.59 & 1.7 & 32.05 & 2.6 \\
\hline & $1 / 2$ & 57.10 & 9 & 44.44 & 15 & 39.63 & 18 & 32.09 & 28 \\
\hline $5 / 2$ & $3 / 2$ & 57.11 & 8 & 44.45 & 13 & 39.65 & 16 & 32.11 & 24 \\
\hline $351 / 2$ & $4 p 3 / 2$ & 78.02 & 142 & 61.17 & 236 & 54.72 & 298 & 44.55 & 457 \\
\hline & $1 / 2$ & 78.18 & 144 & 61.33 & 241 & 54.89 & 305 & 44.71 & 470 \\
\hline $3 p 1 / 2$ & $4 \mathrm{~d} 3 / 2$ & 81.35 & 295 & 63.42 & 486 & 56.59 & 612 & 45.87 & 933 \\
\hline $3 / 2$ & $5 / 2$ & 81.72 & 354 & 63.78 & 584 & 56.95 & 734 & 46.23 & 1119 \\
\hline$"$ & $3 / 2$ & 81.76 & 59 & 63.83 & 98 & 57.01 & 123 & 46.28 & $\$ 87$ \\
\hline $3 \mathrm{~d} 3 / 2$ & $4 \sqrt{5} / 2$ & 83.19 & 653 & 64.76 & 1077 & 57.76 & 1354 & 46.77 & 2065 \\
\hline $5 / 2$ & $7 / 2$ & 83.29 & 698 & 64.86 & 1152 & 57.86 & 1448 & 46.87 & 2206 \\
\hline & $5 / 2$ & 83.32 & 47 & 64.88 & 77 & 57.88 & 96 & 46.90 & 147 \\
\hline $3 p 1 / 2$ & $4 \mathrm{~s} 1 / 2$ & 83.87 & 41 & 65.14 & 65 & 58.04 & 81 & 46.92 & 120 \\
\hline $3 \mathrm{~d} 3 / 2$ & $4 p 3 / 2$ & 83.87 & 2 & 65.21 & 3.2 & 58.13 & 4 & 47.03 & 6 \\
\hline $5 / 2$ & & 84.00 & 18 & .65 .34 & 30 & 58.26 & 37 & 47.16 & 55 \\
\hline $3 / 2$ & $1 / 2$ & 84.05 & 21 & 65.39 & 34 & 58.31 & 42 & 47.21 & 64 \\
\hline $3 p 3 / 2$ & $4 s 1 / 2$ & 84.31 & 84 & 65.58 & 134 & 58.48 & 166 & 47.35 & 249 \\
\hline $4 s 1 / 2$ & $5 p 3 / 2$ & 169.97 & 33 & 133.14 & 55 & 119.06 & 70 & 96.86 & 107 \\
\hline & $1 / 2$ & 170.36 & 34 & 133.53 & 57 & 119.45 & 72 & 97.25 & 111 \\
\hline $4 p 1 / 2$ & $5 d 3 / 2$ & 176.17 & 61 & 137.32 & 101 & 122.54 & 127 & 99.31 & 194 \\
\hline $3 / 2$ & $5 / 2$ & 176.88 & 74 & 138.02 & 122 & 123.23 & 153 & 100.00 & 234 \\
\hline & $3 / 2$ & 177.00 & .12 & 138.14 & 20 & 123.36 & 26 & 100.13 & 39 \\
\hline $4 d 3 / 2$ & $5 f 5 / 2$ & 179.72 & 122 & 139.90 & 202 & 124.78 & 253 & 101.06 & 386 \\
\hline $455 / 2$ & $5 d 5 / 2$ & 179.97 & .1 & 140.08 & .2 & 124.93 & .3 & 101.17 & .4 \\
\hline & $5 g 7 / 2$ & 179.95 & 208 & 140.09 & 343 & 124.95 & 431 & 101.20 & 657 \\
\hline $4 d 5 / 2$ & $5\lceil 7 / 2$ & 179.91 & 131 & 140.09 & 216 & 124.97 & 271 & 101.25 & 414 \\
\hline & $5 / 2$ & 179.97 & 9 & 140.16 & 14 & 125.03 & 18 & 101.31 & 28 \\
\hline $4\lceil 7 / 2$ & $5 \mathrm{~g} 9 / 2$ & 180.04 & 215 & 140.17 & 355 & 125.03 & 447 & 101.29 & 681 \\
\hline & $5 d 5 / 2$ & 180.09 & 2.5 & 140.21 & 4 & 125.06 & 5 & 101.30 & 8 \\
\hline $5 / 2$ & $3 / 2$ & 180.10 & 2.6 & 140.21 & 4 & 125.06 & 5 & 101.30 & 8 \\
\hline $7 / 2$ & $5 g 7 / 2$ & 180.07 & 8 & 140.21 & 13 & 125.08 & 16 & 101.32 & 24 \\
\hline $4 d 3 / 2$ & $5 p 3 / 2$ & 181.34 & 1.1 & 140.98 & 1.7 & 125.67 & 2 & 101.67 & 3 \\
\hline $5 / 2$ & & 181.60 & 10 & 141.24 & 16 & 125.92 & 20 & 101.92 & 30 \\
\hline $3 / 2$ & $1 / 2$ & 181.78 & 11 & 141.42 & 18 & 126.11 & 23 & 102.10 & 34 \\
\hline $4 p 1 / 2$ & $5 s 1 / 2$ & 182.17 & 14 & 141.43 & 22 & 125.99 & 28 & 101.82 & 41 \\
\hline $3 / 2$ & & 183.05 & 29 & 142.30 & 46 & 126.86 & 57 & 102.67 & 86 \\
\hline
\end{tabular}


Table II: Z-dependance analysis of wavelengths $\lambda$ (in $\AA$ ) of some transitions in Li-like ions. Within four per thousond, listed values coincide with $\lambda($ in $A)=911\left(1 / n^{2}-1 / n^{2}\right)^{-1}(2-0)^{-2}$.

\begin{tabular}{|c|c|c|c|c|c|c|c|c|}
\hline $\mathrm{nl} J$ & $n^{\prime} l^{\prime} J^{\prime}$ & $\mathrm{Al}^{10+}$ & $S^{13+}$ & $\mathrm{Cl}^{14+}$ & $\mathrm{K}^{16+}$ & $\mathrm{Ca}^{17+}$ & $\mathrm{TH}^{19+}$ & 0 \\
\hline $3 p 1 / 2$ & $5 d 3 / 2$ & 103.83 & 64.26 & 56.01 & 43.65 & 38.94 & 31.56 & 1.875 \\
\hline $3 / 2$ & $5 / 2$ & 104.02 & 64.45 & 56.20 & 43.83 & 39.13 & 31.74 & 1.903 \\
\hline $3 d 3 / 2$ & $5 / 5 / 2$ & 105.81 & 65.31 & 56.89 & 44.29 & 39.50 & 31.99 & 1.990 \\
\hline $5 / 2$ & $7 / 2$ & 105.86 & 65.37 & 56.94 & 44.34 & 39.55 & 32.04 & 1.999 \\
\hline $3 p 1 / 2$ & $4 d 3 / 2$ & 150.56 & 93.31 & 81.35 & 63.42 & 56.59 & 45.87 & 1.820 \\
\hline $3 / 2$ & $5 / 2$ & 150.95 & 93.68 & 81.72 & 63.78 & 56.95 & 46.23 & 1.859 \\
\hline $3 \mathrm{~d} 3 / 2$ & $4 f 5 / 2$ & 154.72 & 95.50 & 83.19 & 64.76 & 57.76 & 46.77 & 1.986 \\
\hline $5 / 2$ & $7 / 2$ & 154.82 & 95.60 & 83.29 & 64.86 & 57.86 & 46.87 & 1.999 \\
\hline $4 d 3 / 2$ & $5 f 5 / 2$ & 334.23 & 206.32 & 179.72 & 139.90 & 124.78 & 101.06 & 1.986 \\
\hline $5 / 2$ & $7 / 2$ & 334.42 & 206.51 & 179.91 & 140.09 & 124.97 & 101.25 & 1.997 \\
\hline $4 f 5 / 2$ & $5 g 7 / 2$ & 334.67 & 206.58 & 179.95 & 140.09 & 124.95 & 101.20 & 1.997 \\
\hline $7 / 2$ & $9 / 2$ & 334.74 & 206.67 & 180.04 & 140.18 & 125.03 & 101.29 & 2.000 \\
\hline
\end{tabular}

Table III: Z-dependance analysis of probabilitios $A$ (in (ns)-1) of some transitions in Li-like ions. Within two per cent, listed values coincide with $A /(Z-\sigma)^{4}=$ constant, where 0 is taken from Table ll.

\begin{tabular}{|c|c|c|c|c|c|c|c|c|}
\hline $\mathrm{nl} J$ & $n^{\prime} l^{\prime} J^{\prime}$ & $\mathrm{Al}^{10+}$ & s13+ & $\mathrm{Cl}^{14+}$ & $k^{16+}$ & $\mathrm{Ca}^{17+}$ & $\mathrm{Ti}^{19+}$ & $A /(Z-0)^{4}$ \\
\hline $3 p 1 / 2$ & $5 d 3 / 2$ & 42 & 110 & 145 & 239 & 300 & 458 & $2.77 \times 10^{-3}$ \\
\hline $3 / 2$ & $5 / 2$ & 50 & 132 & 174 & 286 & 359 & 547 & $3.35 "$ \\
\hline $3 \mathrm{~d} 3 / 2$ & $5 / 5 / 2$ & 62 & 164 & 216 & 356 & 448 & 682 & 4.26 \\
\hline $5 / 2$ & $7 / 2$ & 66 & 175 & 231 & 380 & 477 & 727 & 4.55 \\
\hline $3 p 1 / 2$ & $4 d 3 / 2$ & 85 & 223 & 295 & 486 & 612 & 933 & 5.55 \\
\hline $3 / 2$ & $5 / 2$ & 102 & 268 & 354 & 584 & 734 & 1119 & $6.71^{\circ}$ \\
\hline $3 \mathrm{~d} 3 / 2$ & $455 / 2$ & 189 & 495 & 653 & 1077 & 1354 & 2065 & $1.29 \times 10^{-2}$ \\
\hline $5 / 2$ & $7 / 2$ & 202 & 530 & 698 & 1152 & 1448 & 2206 & 1.38 \\
\hline $4 d 3 / 2$ & $5 / 5 / 2$ & 35 & 93 & 122 & 202 & 253 & 386 & $2.40 \times 10^{-3}$ \\
\hline $5 / 2$ & $7 / 2$ & 38 & 99 & 131 & 216 & 271 & 414 & 2.58 \\
\hline $4 f 5 / 2$ & $5 g 7 / 2$ & 60 & 158 & 208 & 343 & 431 & 657 & 4.10 \\
\hline $7 / 2$ & $9 / 2$ & 62 & 164 & 215 & 355 & 447 & 681 & 4.26 \\
\hline
\end{tabular}

gain $G$ in $\mathrm{cm}^{-1}$, one obtains

$$
G_{u l}=3.274 \times 10^{-14} s_{u l} M^{1 / 2}(k T)^{-1 / 2} \Delta n_{u l}
$$

where $M$ is the atomic waight ( 12 for carbon 12). An equivalent expression is

$$
G_{u l}=1.616 \times 10^{-23} g_{u} A_{u l} \lambda^{3} M^{1 / 2}(k T)^{-1 / 2} \Delta n_{u l}
$$

where $A_{U l}$ is in (ns)-1 and $\lambda$ in $\AA$ (G, M, KT and $\Delta n$ as above). The hydrodynamical simulation coupled with the collisional-radiative model for $\mathrm{Al}^{10+}$ predicts that a plasnia produced by a Nd-glass-laser Gaussian pulse of $2.55 \times 10^{12} \mathrm{~W} / \mathrm{cm}^{2}$ (2ns duration) gives a maximum gain of $0.6 \mathrm{~cm}^{-1}$ for the $3 \mathrm{~d}-5 \mathrm{f}$ line at $105.8 \AA$, of $2 \mathrm{~cm}^{-1}$ for the $3 \mathrm{~d}-4 \mathrm{f}$ line at $154.8 \AA$, and of $6.5 \mathrm{~cm}^{-1}$ for the $4 \mathrm{f}-5 \mathrm{~g}$ line at $334.7 \AA$. This can be compared with experimental results of Carillon et al. $/ 7 /$. They have observed a gain of $0.8 \mathrm{~cm}^{-1}$ for the $3 \mathrm{~d}-5 \mathrm{f}$ line and $1.5 \mathrm{~cm}^{-1}$ for the $3 \mathrm{~d}-4 \mathrm{f}$ line. However, it must be noted that the calculated maximum gains occur farther from the initial target position, and later after the laser pulse, than observed. This is due to the fact that the simulation ons not reproduce faithrully the plasma giobal recombination (the hydrodynamics code is well suited for hot and dense regions of the plasma but not so well otherwise, and the atomic model must also be improved for low-temperature and-density conditions). If this is not too critical for the aluminium case, it becomes definitely worse for the sulphur. Indeed, a similar work has been undertaken on sulphur. The input laser 
intensity has been increased to $5.25 \times 10^{12} \mathrm{~W} / \mathrm{cm}^{2}$ to account for the higher ionisation potentials, but the results of the complete simulation appear deceiving : all predicted gains fall down dramatically unless the simulation be extended beyond realistic limits of duration and distance from the initial target position. Never theless, starting with $\mathrm{Al}^{10+}$ results and consider ing simple 2 -scailing laws leads to predicted values for $\mathrm{S}^{13+}$ which seem in reasonable agreement with experiment $/ 81$. We are thence now working to improve our models for the next applications.

\section{REFERENCES:}

/1/ A. Sureau, H. Guennou and C. Möller, Europhys. Lett. 5 (1988) 19

/2/ H. Guennou and A. Sureau, J. Phys. B: At. Mol. Phys. 20 (1987) 919

13/ A. Klisnick, H. Guennou and J. Virmont, J. Physique 47 (1986) C6-345

/4/ A. Sureau, H. Guennou and M. Cornille, J. Phys. B: At. Mol. Phys. 17 (1984) 541

15/ H. Van Regemorter, Astrophys. J. 136 ( 1962) 906

16/ M. J. Seaton, Man. Not. Roy. Acad. Sci. 119 ( 1959) 81 Planet. Space Sct. 12 (1964) 55

17/ A. Carillon, A. Klisnick, G. Jamelot, B. Gauthé, F. Gadi and P. Jaeglé, J. Physique 49 (1988) C1-247

18/ A. Carillon, F. Gadi , B. Gauthé, H. Guennou, P. Jaeglé, G. Jamelót, A. Klisnick, C. Möller, and A. Sureau, J. Physique 48 (1987) C9-375 